\title{
Characteristics of Biomedical Beta-Type Titanium Alloy Subjected to Coating
}

\author{
Toshikazu Akahori ${ }^{1}$, Mitsuo Niinomi ${ }^{1}$, Masaaki Nakai ${ }^{1}$, \\ Toshihiro Kasuga ${ }^{2}$ and Michiharu Ogawa ${ }^{3}$ \\ ${ }^{1}$ Institute for Materials Research, Tohoku University, Sendai 980-8577, Japan \\ ${ }^{2}$ Department of Materials Science and Engineering, Nagoya Institute of Technology, Nagoya 466-8555, Japan \\ ${ }^{3} R \&$ D, Daido Steel Co., Ltd., Nagoya 457-8584, Japan
}

Beta-type titanium alloys used in biomedical applications have been developed all over the world. In particular, Ti-29Nb-13Ta-4.6Zr alloy (TNTZ) is one of beta-type titanium alloys for biomedical applications that has been developed by the authors in Japan. Although TNTZ is composed of non-toxic elements such as niobium, tantalum, and zirconium, it still lacks bioactivity, which is the ability to form chemical bonds with living bones. The stems that are parts of artificial hip joints, dental implants, etc., which are made of metallic materials, etc. are required to bond strongly with living bones. However, these stems, dental implants etc., cannot form chemical bond with living bones by themselves. The bioactive surface modification of metallic materials by the application of ceramics is effective in improving the biocompatibility of TNTZ. Calcium phosphate ceramics such as hydroxyapatite $\left(\mathrm{Ca}_{10}\left(\mathrm{PO}_{4}\right)_{6} \mathrm{OH}_{2} ; \mathrm{HAP}\right)$ and $\beta$-tricalcium phosphate $(\beta \text {-Ca } 3 \text { (PO })_{2} ; \beta$-TCP) possess bioactivity. In this study, the characteristics and morphology of TNTZ coated with a calcium phosphate invert-glass-ceramic (CPIG) layer by dip-coating treatment or with a sodium titanate layer by alkali solution treatment are investigated before and after soaking it in a simulated body fluid (SBF).

The bonding strength between a CPIG layer with a thickness of around $5 \mu \mathrm{m}$ and a specimen surface of TNTZ is around $25 \mathrm{MPa}$. No cracks or exfoliations are observed along the boundary between the CPIG layer and the specimen surface. This is the reason why the difference in the thermal expansion coefficients between CPIG layer and TNTZ reduced due to a compositional gradient zone with a thickness of around $3 \mu \mathrm{m}$ in CPIG layer. HAP is formed on the entire surface of the TNTZ specimen after soaking it in the SBF for more than $1728 \mathrm{ks}$. The fatigue properties of TNTZ coated with a CPIG layer are similar to those of as-solutionized TNTZ. A reticulate structure with a thickness of 400 to $800 \mathrm{~nm}$ is formed on the TNTZ specimen surface after soaking it in 3 to $10 \mathrm{kmol} / \mathrm{m}^{3} \mathrm{NaOH}$ solution for $86.4 \mathrm{ks}$ and $172.8 \mathrm{ks}$. HAP is completely formed on the entire surface of the TNTZ specimen when it is soaked in the SBF for $1209.6 \mathrm{ks}$ after being soaked in $5 \mathrm{kmol} / \mathrm{m}^{3} \mathrm{NaOH}$ solution for $172.8 \mathrm{ks}$. [doi:10.2320/matertrans.MRA2007207]

(Received August 22, 2007; Accepted November 22, 2007; Published January 25, 2008)

Keywords: titanium-29 mass\%niobium-13 mass\%tantalum-4.6 mass\%zirconium, bioactive coating, hydroxyapatite, microstructure, mechanical properties

\section{Introduction}

Metallic biomaterials are popularly used as orthopedic implants even in highly loaded parts such as the stems of artificial hip joints. Hence, they are required to possess special mechanical, physical, chemical or biological properties such as high strength, high corrosion resistance, bioactivity, or a Young's modulus close to that of a human bone. For many years, the most common metallic materials employed for medical applications have been $316 \mathrm{~L}$ stainless steel, Co-Cr based alloys, commercially pure (CP) titanium, and Ti-6Al-4V extra low interstitial (ELI) alloy.

Recently, some new titanium alloys comprising beta $(\beta)$ stabilizers such as niobium $(\mathrm{Nb})$ and tantalum $(\mathrm{Ta})$, and a neutral alloying element such as zirconium ( $\mathrm{Zr}$ ) and interstitial oxygen $(\mathrm{O})$ have been developed with the objective obtaining improved mechanical properties and biocompatibility as compared to those of existing alloys. Since CP titanium has poor mechanical properties such as low shear strength, it is not suitable for use in dental and orthopedic implants. Moreover, Ti-6Al-4V ELI alloy is not feasible for use in such implants because of the cytotoxicity of vanadium $(\mathrm{V})$. Most of the recently developed alloys are $\beta$-type titanium alloys with a considerably lower Young's modulus as compared to that of $\alpha$ - or $\alpha+\beta$-type titanium alloys. Another advantage of these alloys is that it is relatively easy to control their mechanical properties through thermomechanical treatment.
The biocompatible Ti-29Nb-13Ta-4.6Zr alloy (TNTZ) developed by the authors has high potential to be used in biomedical applications because of its good mechanical properties such as high specific strength and elongation. ${ }^{1-5)}$ As-solutionized TNTZ has a small Young's modulus of around $60 \mathrm{GPa}$, a very low cytotoxicity similar to that of $\mathrm{CP}$ titanium, and good biocompatibility with living tissues. ${ }^{6}$ ) However, its biocompatibility is inadequate and it lacks bioactivity, which is the ability to form chemical bonds directly with living bones. The stems of artificial joints, dental implants, etc. that are made of metallic materials are required to bond strongly with living bones. However, they cannot form chemical bonds with living bone by themselves.

Bioactive ceramic surface modification is effective in improving the biocompatibility of TNTZ. Calcium phosphate ceramics such as hydroxyapatite $\left(\mathrm{Ca}_{10}\left(\mathrm{PO}_{4}\right)_{6} \mathrm{OH}_{2} ; \mathrm{HAP}\right)$ and $\beta$-tricalcium phosphate $\left(\beta\right.$ - $\mathrm{Ca}_{3}\left(\mathrm{PO}_{4}\right)_{2} ; \beta$-TCP $)$ possess bioactivity. ${ }^{7,8)}$ Bioactivity is required in some parts of artificial substitutes for hard tissues. Many methods for coating HAP and TCP on titanium or titanium alloys have been reported so far. ${ }^{9-16)}$ Among these methods, calcium phosphate invertglass-ceramic (CPIG) coating treatment and alkali solution treatment are simple and highly suitable for TNTZ. ${ }^{17,18)}$ In this study, the morphology of CPIG-coated and alkalisolution-treated surfaces of TNTZ is investigated before and after soaking it in a simulated body fluid (SBF). The change in the mechanical properties of TNTZ after the CPIG-coating treatment, which includes heating, is also investigated. 


\section{Experimental Procedures}

\subsection{Material}

The materials used in this study were hot forged bars of TNTZ with a diameter of $11 \mathrm{~mm}$. The TNTZ bars were solution-treated in vacuum at $1063 \mathrm{~K}$ for $3.6 \mathrm{ks}$, that is, above the $\beta$ transus temperature of TNTZ (around $1013 \mathrm{~K}$ ). Assolutionized TNTZ is referred to as $\mathrm{TNTZ}_{\mathrm{ST}}$.

\subsection{CPIG-coating treatment}

Some of the specimens of $\mathrm{TNTZ}_{\mathrm{ST}}$ were dipped into a slurry of calcium phosphate glass powder $\left(60 \mathrm{CaO}-30 \mathrm{P}_{2} \mathrm{O}_{5}-\right.$ $7 \mathrm{Na}_{2} \mathrm{O}-3 \mathrm{TiO}_{2}$ ) and methanol, and then pulled out at a speed of $1.4 \mathrm{~mm} / \mathrm{s}$. The dipped specimens were dried in air at room temperature for $1.8 \mathrm{ks}$. The thickness of the CPIG layer was controlled to be around $5 \mu \mathrm{m}$ by controlling the concentration of the slurry. After the CPIG-coating treatment, the coated specimens were heated at $1073 \mathrm{~K}$ for $0.9 \mathrm{ks}$, which led to the formation of calcium phosphate ceramics (including TCP); this was followed by furnace cooling to room temperature in order to enhance the bonding between the CPIG layer and the TNTZ substrate. ${ }^{17)}$ The CPIG-coated specimen is referred to as TNTZ $_{\mathrm{DT}}$.

\subsection{Alkali treatment}

TNTZ $_{\text {ST }}$ with a diameter of $5 \mathrm{~mm}$ was polished with a wet emery paper with a grid of \# 600 in order to enhance the bonding with HAP through the anchor effect after immersion in the SBF, and then washed with pure acetone and distilled water in an ultrasonic cleaner. $\mathrm{TNTZ}_{\mathrm{ST}}$ was subjected to alkali treatment by soaking in $\mathrm{NaOH}$ aqueous solutions with concentrations of 3,5 , and $10 \mathrm{kmol} / \mathrm{m}^{3}$ at $333 \mathrm{~K}$ for 86.4 and $172.8 \mathrm{ks}$. After the alkali treatment, the specimens were washed with distilled water, and dried at $313 \mathrm{~K}$ for $86.4 \mathrm{ks}$. The alkali-treated specimens are referred to as $\mathrm{TNTZ}_{\mathrm{AT}}$.

\subsection{Soaking in SBF}

In order to investigate HAP formation on the $\mathrm{TNTZ}_{\mathrm{DT}}$ and $\mathrm{TNTZ}_{\mathrm{AT}}$ surfaces, these surfaces were soaked in the SBF $\left(\mathrm{Na}^{+}: 142, \mathrm{~K}^{+}: 5, \mathrm{Mg}^{+}: 1.5 \mathrm{Ca}^{+}: 2.5, \mathrm{Cl}^{-}: 103, \mathrm{HCO}_{3}{ }^{-}: 27\right.$, $\left.\mathrm{HPO}_{4}{ }^{2-}: 1 \mathrm{SO}_{4}{ }^{2-}: 0.5 \mathrm{~mol} / \mathrm{m}^{3}\right)^{13)}$ at $310 \mathrm{~K}$ for $604.8 \mathrm{ks}$ to $1814.4 \mathrm{ks}$; the $\mathrm{pH}$ and ion concentrations of the SBF were similar to those of human blood plasma.

\subsection{Evaluation of microstructure}

Microstructural evaluations were carried out by using a scanning electron microscope (SEM) equipped with an energy dispersive X-ray (EDX) analyzer, an Auger electron spectrometer (AES), and an X-ray diffractometer (XRD).

\subsection{Mechanical tests before and after CPIG-coating treatment}

Specimens with a diameter of $10 \mathrm{~mm}$ and a thickness of $2.0 \mathrm{~mm}$ were machined from TNTZ $_{\mathrm{DT}}$ for Vickers hardness tests. The surfaces of these specimens were polished using a wet emery paper with a grid of \# 600 and washed with pure acetone. Subsequently, buff polishing was performed on these specimens. The hardness of the buff polished specimen was measured using a Vickers hardness tester with a load of $0.49 \mathrm{~N}$ and a holding time of $15 \mathrm{~s}$.
Columnar specimens of $\mathrm{TNTZ}_{\mathrm{DT}}$ with a diameter of $10 \mathrm{~mm}$ and a height of $20 \mathrm{~mm}$ were used to evaluate the tensile bonding strength of the coating layers. A bonding agent used in dental applications (orthomite super bond) was applied to the surface of the coating layer of each specimen. The surface with the bonding agent was then bonded with a columnar stainless steel fixture, whose size was identical to that of the columnar specimens. Subsequently, the bonded specimens were dried in air at room temperature for $86.4 \mathrm{ks}$ and subjected to the tensile bonding test. The tests were conducted at a crosshead speed of $1.67 \times 10^{-5} \mathrm{~m} / \mathrm{s}$ in air at room temperature using an Instron-type tensile testing machine. In order to enhance the adhesion between the TNTZ substrate and the coating layer before the CPIG-coating treatment, the specimen surfaces were subjected to carbon blasting at a pressure of $0.5 \mathrm{MPa}$, which resulted in an average surface roughness of around $1.29 \mu \mathrm{m}$.

For the tensile and fatigue tests, dog-bone-type tensile specimens with a diameter of $10 \mathrm{~mm}$ and a gage length of $20 \mathrm{~mm}$ were machined from $\mathrm{TNTZ}_{\mathrm{ST}}$. These specimens were then subjected to carbon blasting after polishing with a wet emery paper with a grid of \# 600; subsequently, they were washed with pure acetone before the CPIG-coating treatment. For the fatigue test, the specimens were also buff polished in the solutionized condition to obtain a mirror surface with an average roughness of around $0.01 \mu \mathrm{m}$ after polishing with a wet emery paper with a grid of \# 1500 as comparison. The tensile test for each tensile specimen was conducted using an Instron-type machine at a crosshead speed of $8.33 \times 10^{-6} \mathrm{~m} / \mathrm{s}$ in air at $295 \mathrm{~K}$. The load was detected by the load cell of the machine. The strain was detected by using a strain gage attached to the gage part of the specimen.

The fatigue tests were conducted on the fatigue test specimens by using an electro servo-hydraulic-machine. The fatigue tests were conducted at a frequency of $10 \mathrm{~Hz}$ and a stress ratio $\mathrm{R}$ of 0.1 in air at $295 \mathrm{~K}$. The maximum cyclic stress, at which the specimen did not fail for $10^{7}$ cycles, was defined as the fatigue limit in this study.

\section{Results and Discussion}

\subsection{Morphology of TNTZ $_{\mathrm{DT}}$ before and after soaking it in SBF}

Figure 1 shows the SEM micrographs of the specimen surface and cross sections of $\mathrm{TNTZ}_{\mathrm{DT}}$. The CPIG layer exhibits a microstructure comprising a large number of pores; these pores are a few micrometers in diameter and around $5 \mu \mathrm{m}$ in thickness. No cracks are observed at the boundary between the CPIG layer and the TNTZ substrate, and no exfoliations of the CPIG layer are observed, although the thermal expansion coefficients of $\mathrm{CP}$ titanium and CPIG range from $8 \times 10^{-6}$ to $10 \times 10^{-6} \mathrm{deg}^{-1}$ and $16 \times 10^{-6}$ to $18 \times 10^{-6} \mathrm{deg}^{-1}$, respectively. ${ }^{18)}$ A large number of cracks and exfoliations were observed in the CPIG layer with a thickness of $15 \mu \mathrm{m}$ of TNTZ after heating. ${ }^{19)}$ The optimum thickness of the CPIG layer is considered to be around $5 \mu \mathrm{m}$.

The matrix of $\mathrm{TNTZ}_{\mathrm{DT}}$ comprises $\beta$ phase grains with a diameter of around $20 \mu \mathrm{m}$. Precipitatd alpha $(\alpha)$ and omega $(\omega)$ phases, which were expected to exist in the matrix, were 


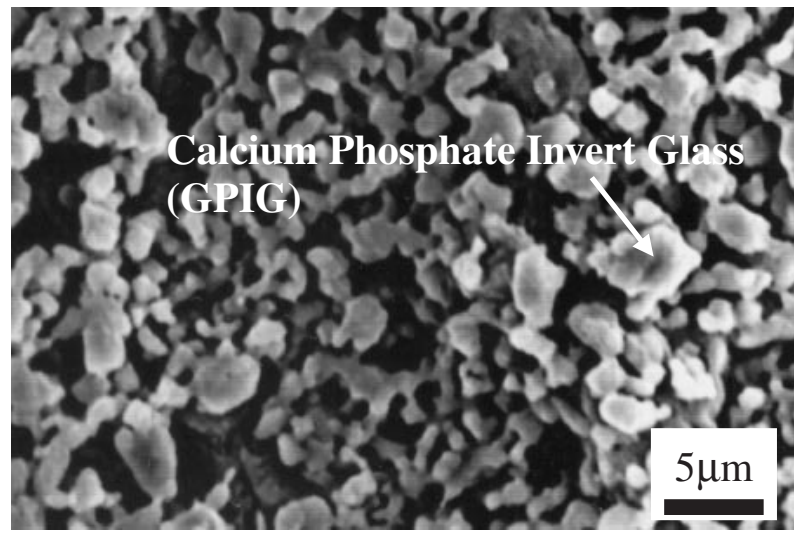

(a) Surface of $\mathrm{TNTZ}_{\mathrm{DT}}$

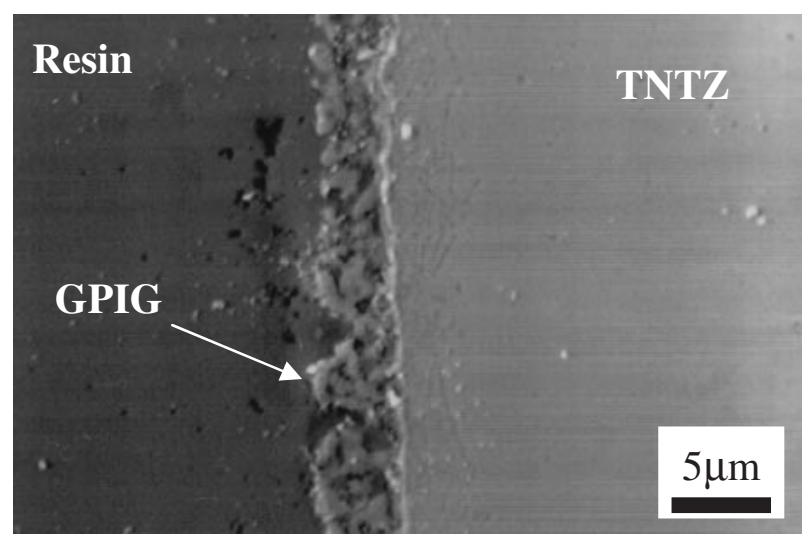

(b) Cross section of $\mathrm{TNTZ}_{\mathrm{DT}}$

Fig. 1 SEM micrographs of morphologies of (a) Ti-29Nb-13Ta-4.6Zr (TNTZ) coated with calcium phosphate invert-glass (CPIG) layer $\left(\mathrm{TNTZ}_{\mathrm{DT}}\right)$ and $(\mathrm{b})$ its cross section of near CPIG layer.

not observed in the SEM micrographs, probably due to their super fine precipitation.

Figure 2 shows an SEM micrograph of the $\mathrm{TNTZ}_{\mathrm{DT}}$ cross section and results of the line analysis of elements along the indicated line obtained by using the EDX analyzer. The concentration of each element exhibits a gradient within the layer near the TNTZ substrate. Thus, a compositional gradient zone that is around $3 \mu \mathrm{m}$ in thickness is formed. The titanium concentration in the zone increases with a decrease in the distance from the CPIG surface toward the substrate. On the other hand, the calcium and phosphorus concentrations in the zone increase with an increase in the distance from the TNTZ substrate.

Figure 3 shows the XRD profiles of $\mathrm{TNTZ}_{\mathrm{DT}}$ measured at an each different depth from the specimen surface to $1000 \mu \mathrm{m}$ from the interface between CPIG and TNTZ substrate. The XRD profile of the TNTZ $\mathrm{DT}_{\mathrm{DT}}$ surface shows the peaks of the $\beta$ TCP, $\beta$-CPP ( $\beta$-calcium pyrophosphate; $\beta$ - $\left.\mathrm{Ca}_{2} \mathrm{P}_{2} \mathrm{O}_{7}\right), \beta$ phase, $\alpha$ phase, and $\mathrm{TiO}_{2}$ (rutile). The XRD profiles indicate that the coating layers comprise a large amount of $\beta$-TCP and a small amount of $\beta$-CPP. The peak of $\mathrm{TiO}_{2}$ is clearly observed from the surface of the CPIG to a depth of $20 \mu \mathrm{m}$. This is because TNTZ is heated in air during the CPIGcoating treatment in this study. The peak of $\mathrm{TiO}_{2}$ was not observed on the surface of $\mathrm{TNTZ}_{\mathrm{ST}}{ }^{20)}$ The peak of the $\alpha$

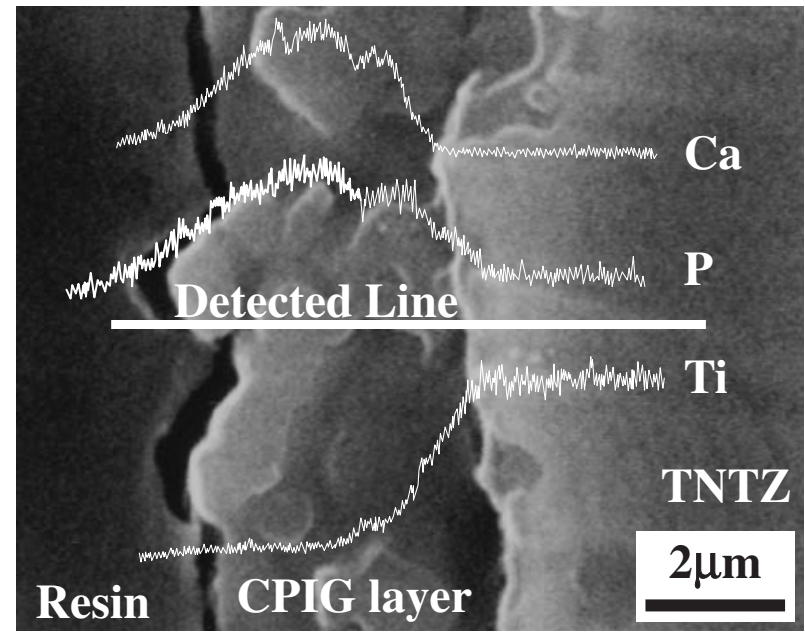

Fig. 2 SEM micrograph of cross section of $\mathrm{TNTZ}_{\mathrm{DT}}$, and $\mathrm{Ti}, \mathrm{P}$ and $\mathrm{Ca}$ concentration profiles along detected line.

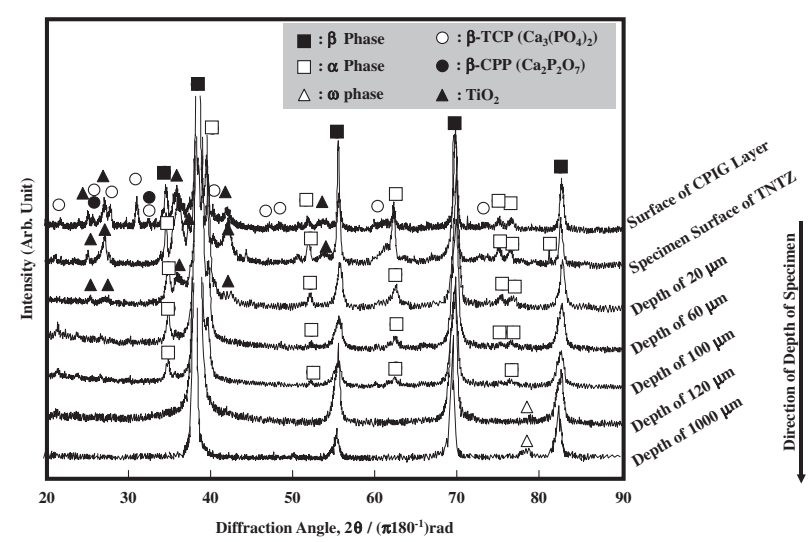

Fig. 3 X-ray diffraction profiles of $\mathrm{TNTZ}_{\mathrm{DT}}$ as a function of distance from surface of specimen.

phase is also observed at a depth of $100 \mu \mathrm{m}$, where the oxygen-rich region ( $\alpha$ case), which comprises the $\alpha$ phase, may be formed.

HAP was partly formed on the coating layer after soaking $\mathrm{TNTZ}_{\mathrm{DT}}$ in SBF for $864 \mathrm{ks}$. The coating layer is completely covered with HAP after soaking $\mathrm{TNTZ}_{\mathrm{DT}}$ in the SBF for more than $1728 \mathrm{ks}$ as shown in Fig. 4.

\subsection{Bonding strength of CPIG and mechanical proper- ties of TNTZ}

The tensile bonding strength of the CPIG layer on the TNTZ substrate was around $25.0 \mathrm{MPa}$; this value is considerably greater than that of CPIG on pure titanium or Ti-6Al$4 \mathrm{~V}$, where the tensile bonding strength of CPIG is in the range of 4.15 to $13.9 \mathrm{MPa}$, and that of HAp powders or an AW glass layer mechanically coated on CP titanium and its alloys. ${ }^{21,22)}$ Fractured CPIG and a portion of orthomite super bond were observed on the fracture surfaces of all the TNTZ $_{\text {DT }}$ specimens obtained from the tensile bonding tests, but TNTZ substrates were not observed. In other words, the coating layer is bonded strongly with the TNTZ substrate due to the presence of the compositional gradient zone within the 


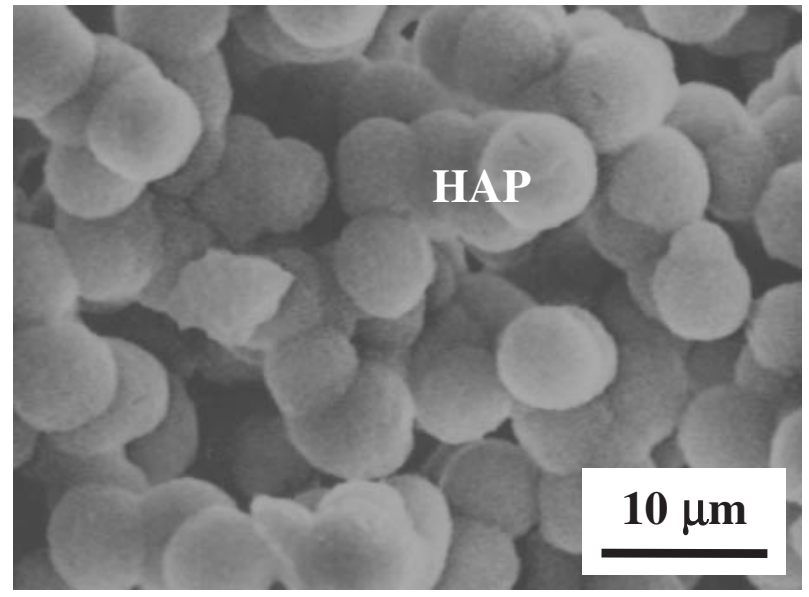

Fig. 4 SEM micrograph on specimen surface of $\mathrm{TNTZ}_{\mathrm{DT}}$ after soaking in SBF for $1209.6 \mathrm{ks}$.

CPIG layer, where titanium phosphate near the surface of the TNTZ seems to be formed by a reaction between the $\beta$-CPP and the calcium phosphate including some $\mathrm{Na}_{2} \mathrm{O}$ and $\mathrm{TiO}_{2}$ during the heating at $1073 \mathrm{~K}$ for $0.9 \mathrm{ks},{ }^{18}$ ) and the anchor effect of the rough TNTZ surface formed by carbon blasting. In addition, it is difficult to investigate the true tensile bonding strength of CPIG layer due to the greater strength of the bonding of CPIG layer with the TNTZ substrate as compared to that of orthomite super bond.

The Vickers hardness test revealed the presence of a hardness gradient near the surface of the TNTZ substrate because the oxide layer and $\alpha$ case existed near the surface of the TNTZ substrate. The Vickers hardness near the surface of the TNTZ substrate and at a depth of around $600 \mu \mathrm{m}$ from the surface was $286 \mathrm{HV}$ and $240 \mathrm{HV}$, respectively.

The tensile strength of $\mathrm{TNTZ}_{\mathrm{ST}}$ was $549 \mathrm{MPa}$ and its elongation was $41.6 \%$. The tensile strength and elongation of $\mathrm{TNTZ}_{\mathrm{DT}}$ were $713 \mathrm{MPa}$ and $21.7 \%$, respectively. The increase in the strength of $\mathrm{TNTZ}_{\mathrm{DT}}$ can be mainly attributed to age hardening due to the precipitation of the $\omega$ and $\alpha$ phases (which enhance the tensile strength and $0.2 \%$ proof stress) during very slow cooling in air, as shown in Fig. 3, and solid solution hardening caused by the oxygen-rich layer near the TNTZ surface.

Figure 5 shows the relationship between the maximum cyclic stress and the number of cycles to failure for $\mathrm{TNTZ}_{\mathrm{ST}}$ and $\mathrm{TNTZ}_{\mathrm{DT}}$. The fatigue strength of $\mathrm{TNTZ}_{\mathrm{DT}}$ is similar to that of TNTZ $\mathrm{ST}_{\mathrm{ST}}$ in low-cycle fatigue life $\left(<10^{5}\right.$ cycles) and high-cycle fatigue life ( $>10^{5}$ cycles) regions. The fatigue limits of $\mathrm{TNTZ}_{\mathrm{ST}}$ and $\mathrm{TNTZ}_{\mathrm{DT}}$ are $330 \mathrm{MPa}$ and $325 \mathrm{MPa}$, respectively. However, the fatigue ratio ( $f$; fatigue limit/ tensile strength) of $\mathrm{TNTZ}_{\mathrm{DT}}$ is 0.46 , which is less than that of $\mathrm{TNTZ}_{\mathrm{ST}}$ (0.60). In general, the fatigue strength increases with the tensile strength and $0.2 \%$ proof stress. The tensile strength and $0.2 \%$ proof stress of $\mathrm{TNTZ}_{\mathrm{DT}}$ are considerably greater than those of $\mathrm{TNTZ}_{\mathrm{ST}}$. This is mainly attributed to the difference in the surface roughness between $\mathrm{TNTZ}_{\mathrm{DT}}$ and TNTZ $_{\mathrm{ST}}$, whose surface carbon blasted and buff polished, respectively. However, this fact needs to be confirmed by further investigation.

All the fatigue cracks of $\mathrm{TNTZ}_{\mathrm{DT}}$ initiated at the very edge

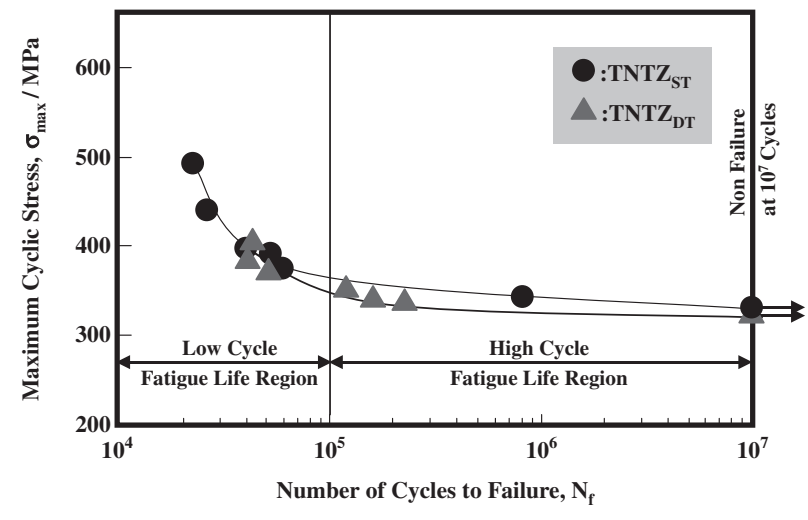

Fig. 5 S-N curves of as-solutionized TNTZ $\left(\mathrm{TNTZ}_{\mathrm{ST}}\right)$ and $\mathrm{TNTZ}_{\mathrm{DT}}$.

of the specimen surface comprised $\mathrm{TiO}_{2}$ and $\alpha$ case, whose roughness is relatively high. On the other hand, the fatigue cracks of $\mathrm{TNTZ}_{\mathrm{ST}}$ initiated in the $\beta$ phases of the fatigue specimen surface. Striations were formed in the stable crack propagation area in all the specimens studied.

The exfoliation of the CPIG layer on the specimen surface of $\mathrm{TNTZ}_{\mathrm{DT}}$ was not observed after the fatigue tests.

\subsection{Morphology of $\mathrm{TNTZ}_{\mathrm{AT}}$ before and after soaking it in SBF}

Figure 6 shows SEM micrographs of the alkali-treated TNTZ $\left(\mathrm{TNTZ}_{\mathrm{AT}}\right)$ specimen surfaces treated in 3, 5, and $10 \mathrm{kmol} / \mathrm{m}^{3} \mathrm{NaOH}$ solutions at $333 \mathrm{~K}$ for $86.4 \mathrm{ks}$ and $172.8 \mathrm{ks}$. A rough reticulate structure can be observed on the surface of $\mathrm{TNTZ}_{\mathrm{AT}}$, as shown in Fig. 6. With high magnification, a very fine reticulate structure can be observed on all the specimens, as representatively shown in Fig. 7. The XRD analysis detected a peak of $\mathrm{Na}_{2} \mathrm{Ti}_{5} \mathrm{O}_{11}$ or $\mathrm{Na}_{2} \mathrm{Ti}_{6} \mathrm{O}_{13}$ on the specimen surfaces of $\mathrm{TNTZ}_{\mathrm{AT}}$ soaked in 5 and 10 $\mathrm{kmol} / \mathrm{m}^{3} \mathrm{NaOH}$ solutions. CP titanium and its alloys are well known to be covered with a titanium oxide film such as $\mathrm{TiO}_{2}$. The oxide film on TNTZ might be composed of many types of oxides such as $\mathrm{Nb}_{2} \mathrm{O}_{5}, \mathrm{Ta}_{2} \mathrm{O}_{5}$, and $\mathrm{ZrO}_{2}$.

The dissolution reaction of a titanium oxide film in an alkali solution is as follows: ${ }^{13)}$

$$
\mathrm{TiO}_{2}+\mathrm{OH}^{-} \rightarrow \mathrm{HTiO}_{3}^{-}
$$

A small amount of niobium oxide film may dissolve according to the following reaction: ${ }^{23)}$

$$
\mathrm{Nb}_{2} \mathrm{O}_{5}+2 \mathrm{OH}^{-} \rightarrow 2 \mathrm{NbO}_{3}^{-}+\mathrm{H}_{2} \mathrm{O}
$$

Then, the negatively charged specimen surfaces combine with positively charged alkali ions, resulting in the formation of sodium titanate and niobate hydrogel. When soaked into the SBF, Na ions are released from the hydrogel layer and the negatively charged hydronium ions in the SBF incorporated mainly with the Ti-OH group, which may be less in amount as compared with CP titanium fully covered with $\mathrm{TiO}_{2}$, on the specimen surface. $\mathrm{ZrO}_{2}$ and $\mathrm{Ta}_{2} \mathrm{O}_{5}$ may react slightly according to equations (1) and (2), respectively, although there is a possibility of a change in their reactions in the SBF at $\mathrm{pH} 7.4$ because of their different points of zero charge.

Figure 8 shows the AES results for $\mathrm{TNTZ}_{\mathrm{AT}}$ soaked in 


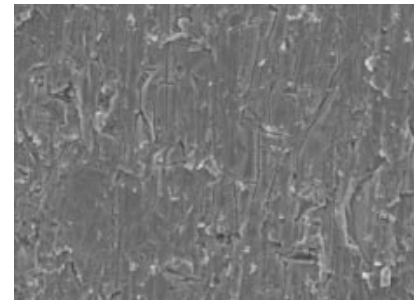

(a) $3 \mathrm{~mol} / 86.4 \mathrm{ks}$

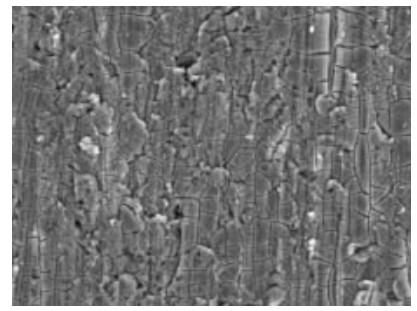

(b) $5 \mathrm{~mol} / 86.4 \mathrm{ks}$

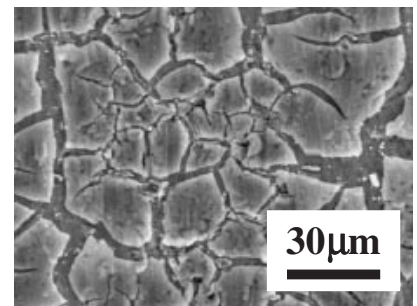

(c) $10 \mathrm{~mol} / 86.4 \mathrm{ks}$

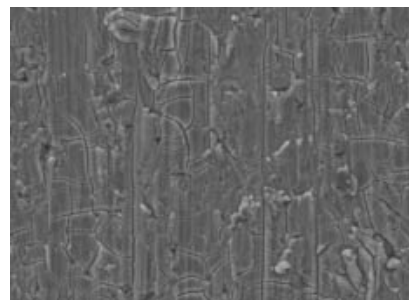

(d) $3 \mathrm{~mol} / 172.8 \mathrm{ks}$

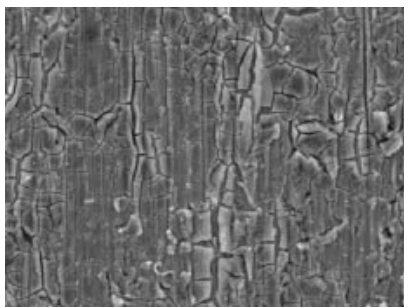

(e) $5 \mathrm{~mol} / 172.8 \mathrm{ks}$

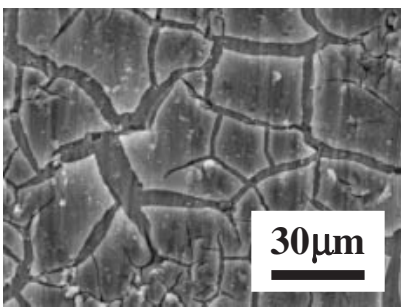

(f) $10 \mathrm{~mol} / 172.8 \mathrm{ks}$

Fig. 6 SEM micrographs on specimen surfaces of TNTZ after soaking in 3, 5 and $10 \mathrm{kmol} / \mathrm{m}^{3} \mathrm{NaOH}$ solutions at $333 \mathrm{~K}$ for $86.4 \mathrm{ks}$ and $172.8 \mathrm{ks}$.

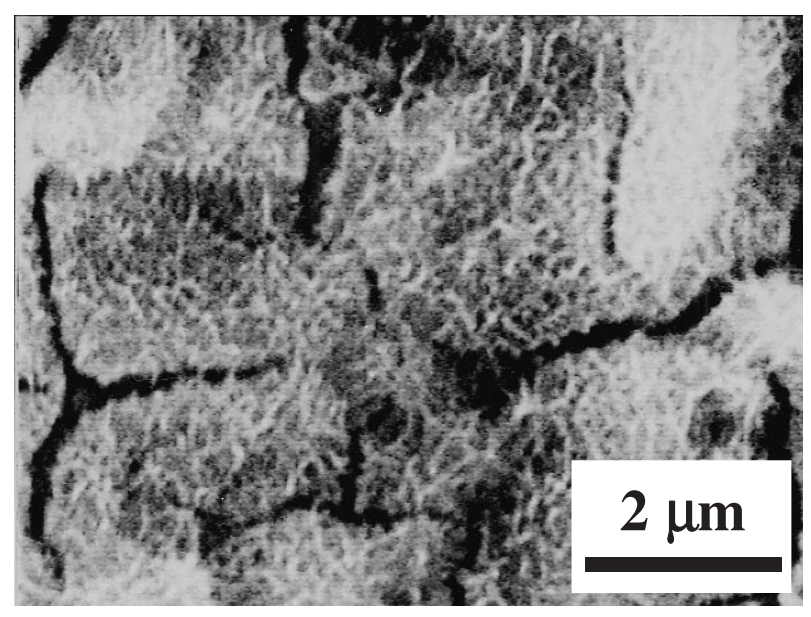

\section{$5 \mathrm{~mol} / 172.8 \mathrm{ks}$}

Fig. 7 Representative SEM micrograph on specimen surface of TNTZ after soaking in $5 \mathrm{kmol} / \mathrm{m}^{3} \mathrm{NaOH}$ solutions at $333 \mathrm{~K}$ for $172.8 \mathrm{ks}$ with a high magnification.

3,5 , and, $10 \mathrm{kmol} / \mathrm{m}^{3} \mathrm{NaOH}$ solutions at $333 \mathrm{~K}$ for $86.4 \mathrm{ks}$ and $172.8 \mathrm{ks}$ as a function of the distance from the surface of the specimen. The thickness of the oxide film on TNTZ was measured to be around $10 \mathrm{~nm}$ before the alkali treatment when the points of intersection between the oxygen and titanium intensity profiles obtained from the AES were set at the interface between the oxide film and the matrix. ${ }^{24)}$ After
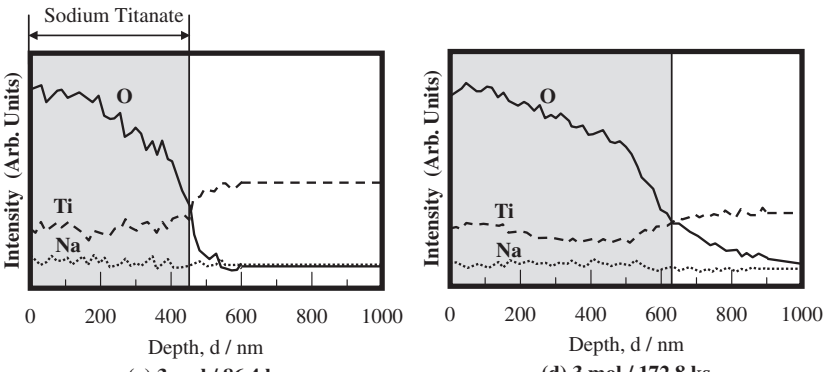

(a) $3 \mathrm{~mol} / 86.4 \mathrm{ks}$

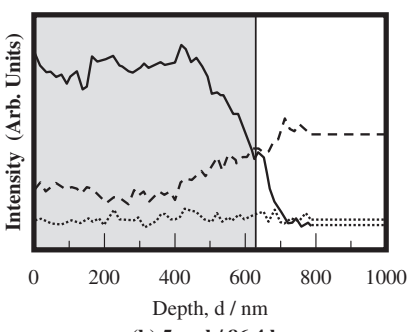

(d) $3 \mathrm{~mol} / 172.8 \mathrm{ks}$

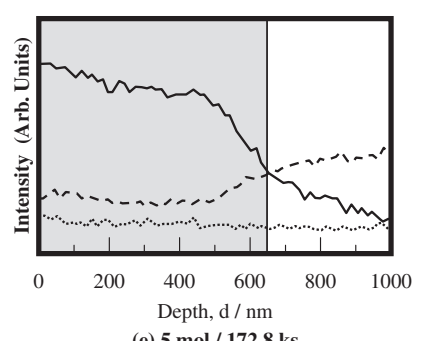

(e) $5 \mathrm{~mol} / 172.8 \mathrm{ks}$
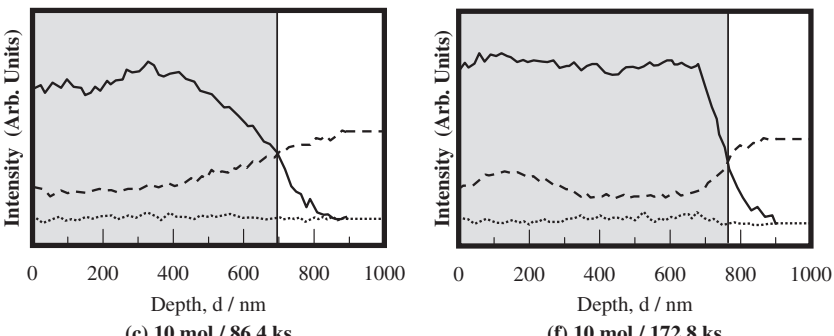

Fig. 8 Results of AES on specimen surfaces of TNTZ in 3, 5 and 10 $\mathrm{kmol} / \mathrm{m}^{3} \mathrm{NaOH}$ solutions at $333 \mathrm{~K}$ for $86.4 \mathrm{ks}$ and $172.8 \mathrm{ks}$.

the alkali treatment, a sodium titanate film, which could comprise sodium niobate, oxygen, and sodium, was observed. The thickness of the reticulate product appeared to increase proportionally from 400 to $800 \mathrm{~nm}$ with the molar concentration of the $\mathrm{NaOH}$ solution and the soaking time in the solution, although changes in all the profiles of $\mathrm{Na}$, which had small fluctuations, were nearly equal within the sodium titanate film.

HAP was not formed on all the specimen surfaces of $\mathrm{TNTZ}_{\mathrm{AT}}$ that were soaked in the SBF for $604.8 \mathrm{ks}$; it is formed only on the specimen surfaces of $\mathrm{TNTZ}_{\mathrm{AT}}$ that were soaked in SBF for $1209.6 \mathrm{ks}$ after being soaked in 3, 5, and, $10 \mathrm{kmol} / \mathrm{m}^{3} \mathrm{NaOH}$ solutions, as shown in Fig. 9. The HAP formation on the specimen surfaces of $\mathrm{TNTZ}_{\mathrm{AT}}$ soaked in 3 and $5 \mathrm{kmol} / \mathrm{m}^{3} \mathrm{NaOH}$ solutions is partial and complete, respectively. On the other hand, HAP is partly exfoliated on the specimen surface of $\mathrm{TNTZ}_{\mathrm{AT}}$ soaked in the $10 \mathrm{kmol} / \mathrm{m}^{3}$ $\mathrm{NaOH}$ solution.

The exchange between the $\mathrm{Na}$ ion and the hydronium ion in the SBF results in a $\mathrm{pH}$ increase in the fluid surrounding the specimen surface. This $\mathrm{pH}$ increase leads to an increase in the ionic activity product of HAP according to the following equilibrium in the SBF: ${ }^{13)}$

$$
10 \mathrm{Ca}^{2+}+6 \mathrm{PO}_{4}{ }^{3-}+2 \mathrm{OH}^{-} \leftrightarrow \mathrm{Ca}_{10}\left(\mathrm{PO}_{4}\right)_{6}(\mathrm{OH})_{2}
$$

The apatite nuclei grow with an increase in the consumption of calcium and phosphate ions from the surrounding fluid. It has been reported that the HAP formation on the specimen surface of CP titanium is enhanced with an increase 


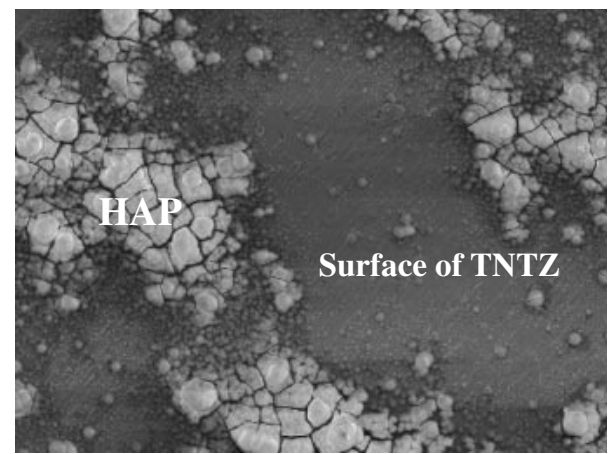

(a) $3 \mathrm{~mol} / 172.8 \mathrm{ks}$

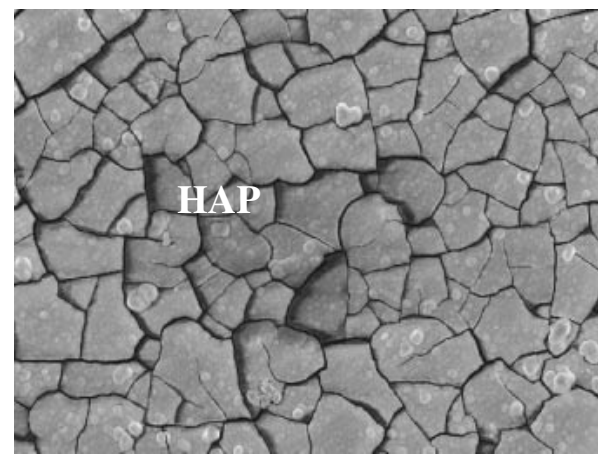

(b) $5 \mathrm{~mol} / 172.8 \mathrm{ks}$

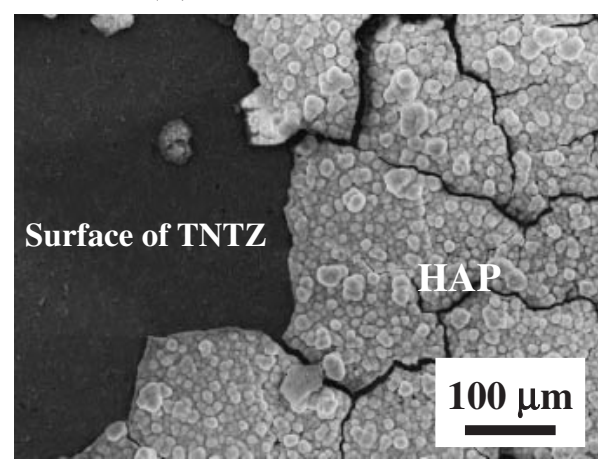

(c) $10 \mathrm{~mol} / 172.8 \mathrm{ks}$

Fig. 9 SEM micrographs on specimen surfaces of TNTZ dipping in SBF for for $1209.6 \mathrm{ks}$ after soaking in 3,5 and $10 \mathrm{kmol} / \mathrm{m}^{3} \mathrm{NaOH}$ solution at $333 \mathrm{~K}$ for $172.8 \mathrm{ks}$.

in the molar concentration and the soaking time in the alkali solution. In particular, the HAP formation is complete on the specimen surface soaked in the SBF for $172.8 \mathrm{ks}$ after being soaked in 5 and $10 \mathrm{kmol} / \mathrm{m}^{3} \mathrm{NaOH}$ solution at temperatures between $313 \mathrm{~K}$ and $333 \mathrm{~K}$ for $86.4 \mathrm{ks}$. A similar trend is observed for $\mathrm{TNTZ}_{\mathrm{AT}}$, although the HAP formation takes a considerably longer time as compared to the case of alkalitreated CP titanium. The HAP formation might be delayed due to the existence of different types of oxide films, which depend on according to the alloying elements. The formation of HAP by alkali treatment on the specimen surface of $\mathrm{CP}$ titanium is the fastest when compared with the surfaces of $\mathrm{CP}$ niobium, CP tantalum, and CP zirconium. ${ }^{25-29)}$ The formability of HAP on CP tantalum and $\mathrm{CP}$ zirconium is relatively high. On the other hand, The formability seems to be lower for $\mathrm{CP}$ niobium, although the data reported is very poor. Therefore, a further detailed investigation is required to clarify this issue.

\section{Conclusions}

The morphologies of the surfaces of a $\beta$-type titanium alloy, TNTZ, fabricated for biomedical applications were investigated by subjecting it to a CPIG coating and alkali solution treatments. The change in the mechanical properties of TNTZ resulting from the CPIG coating treatment was also investigated. The following results were obtained.

(1) A compositional gradient zone with a thickness of around $3 \mu \mathrm{m}$ exists within the CPIG layer near the surface of the TNTZ substrate. The tensile bonding strength between TNTZ and the CPIG layer is around $25 \mathrm{MPa}$.

(2) HAP is partly formed on the CPIG coating layer after soaking it in the SBF for $864 \mathrm{ks}$. The CPIG coating layer is completely covered with HAP after soaking it in the SBF for more than $1728 \mathrm{ks}$.

(3) The tensile strength of TNTZ with CPIG coating is $713 \mathrm{MPa}$, which is around $160 \mathrm{MPa}$ greater than that of as-solutionized TNTZ. On the other hand, its elongation is $21.7 \%$, which is half of that of as-solutionized TNTZ. The fatigue limit of TNTZ with CPIG coating is nearly equal to that of as-solutionized TNTZ.

(4) The specimen surfaces of alkali-treated TNTZ treated in 3,5 , and $10 \mathrm{kmol} / \mathrm{m}^{3} \mathrm{NaOH}$ solutions at $333 \mathrm{~K}$ for $86.4 \mathrm{ks}$ and $172.8 \mathrm{ks}$ exhibit a rough reticulate structure, which is found to comprise a very fine reticulate structure in high-magnification SEM observations. Only EDX profiles on the specimen surfaces of alkalitreated TNTZ in 5 and $10 \mathrm{kmol} / \mathrm{m}^{3} \mathrm{NaOH}$ solutions exhibit a peak of $\mathrm{Na}_{2} \mathrm{Ti}_{5} \mathrm{O}_{11}$ or $\mathrm{Na}_{2} \mathrm{Ti}_{6} \mathrm{O}_{13}$.

(5) HAP is partly and completely formed on the specimen surfaces of alkali-treated TNTZ treated in 3 and $5 \mathrm{kmol} / \mathrm{m}^{3} \mathrm{NaOH}$ solutions for $172.8 \mathrm{ks}$, respectively, after soaking them in SBF for $1209.6 \mathrm{ks}$. On the other hand, the exfoliation of HAP is observed on the surface of alkali-treated TNTZ treated in $10 \mathrm{kmol} / \mathrm{m}^{3} \mathrm{NaOH}$ solution for $172.8 \mathrm{ks}$.

\section{REFERENCES}

1) D. Kuroda, M. Niinomi, M. Morinaga, Y. Kato and T. Yashiro: Mater. Sci. Eng. A A243 (1998) 244-249.

2) M. Niinomi, D. Kuroda, K. Fukunaga, M. Morinaga, Y. Kato, T. Yashiro and A. Suzuki: Mater. Sci. Eng. A A263 (1999) 193-199.

3) M. Ikeda, S. Komatsu, I. Sowa and M. Niinomi: Met. Mater. Trans. A 33A (2002) 487-493.

4) D. Kuroda, M. Niinomi, T. Akahori, H. Fukui, A. Suzuki and J. Hasegawa: Structural Biomaterials for the $21^{\text {st }}$ Century, Eds. M. Niinomi, T. Okabe, E. H. Tallef, D. R. Lesure and H. E. Lippard, (TMS, 2001) pp. 99-106.

5) M. Niinomi, T. Hattori and S. Niwa: Biomaterials in Orthopedics, Eds. M. J. Yaszemski, D. J. Trantolo, K. U. Lewandrowski, V. Hasirci, D. E. Altobelli and D. L. Wise, (Marcel Dekker, INC, 2004) pp. 41-62.

6) M. Niinomi, T. Hattori, K. Morikawa, T. Kasuga, A. Suzuki, H. Fukui and S. Niwa: Mater. Trans. 43 (2002) 2970-2977.

7) L. L. Hench: Bioceramics 74 (1991) 1487-1510.

8) R. H. Doremus: Bioceramics 27 (1992) 285-297.

9) W. R. Lancefield: An Introduction to Bioceramics, Edts. L. L. Hench and J. Wilson, (1993) pp. 223-238.

10) Y. Fan, K. Duan and R. Wang: Biomaterials 26 (2005) 1623-1632.

11) T. Nonami, K. Naganuma and T. Kameyama: Materia Japan 37 (1998) $856-858$. 
12) S. Ding, T. Huang and C. Kao: Surf. Coating Tech. 165 (2003) 248257.

13) H. Kim, F. Miyaji, T. Kokubo and T. Nakamura: J. Cera. Soc. JPN 105 (1997) 111-116.

14) T. Hanawa, M. Kon, H. Ukai, K. Murakami, Y. Miyamoto and K. Asaoka: J. Biomedical Mater. Res. 34 (1997) 273-278.

15) V. Nelea, C. Morosanu, M. Iliescu and I. N. Mihailescu: Surf. Coating Tech. 173 (2003) 315-322.

16) F. Liang, L. Zhou and K. Wang: Surf. Coating Tech. 165 (2003) 133 139.

17) T. Kasauga, T. Mizuno, M. Watanabe, M. Nogami and M. Niinomi: Biomaterials 22 (2001) 577-582.

18) T. Kasuga: Materia. Japan 39 (2000) 250-255.

19) M. Niinomi, T. Akahori, T. Yamaguchi, T. Kasuga, H. Fukui and A. Suzuki: J. Jpn. Inst. Metals 67 (2003) 604-613.

20) T. Akahori, M. Niinomi, K. Ishimizu, H. Fukui and A. Suzuki: J. Jpn. Inst. Metals 67 (2003) 652-660.
21) X. Zheng, M. Huang and C. Ding: Biomaterials 21 (2000) 841-849.

22) Y. C. Tsui, C. Doyle and T. W. Clyne: Biomaterials 19 (1998) 20152029.

23) R. Rosenberg, D. Starosvetsky and I. Gotman: J. Mater. Sci. Letters 22 (2003) 29-32.

24) B. H. Lee, Y. D. Kim, J. H. Shin and K. H. Lee: J. Biomed. Mater. Res. 61 (2002) 466-473.

25) H. M. Kim, F. Miyaji, T. Kokubo and T. Nakamura: J. Mater. Sci. (Mater. Medicine) 8 (1997) 341-347.

26) H. M. Kim, F. Miyaji, T. Kokubo and T. Nakamura: J. Biomed. Mater. Res. 32 (1996) 409-417.

27) T. Miyazaki, H. Kim, T. Kokubo, C. Ohtsuki and T. Nakamura: J. Cera. Soc. Japan 109 (2001) 923-933.

28) T. Miyazaki, H. M. Kim, F. Miyaji, T. Kokubo and H. Kato: J. Biomed. Mater. Res. 50 (2000) 35-42.

29) M. Uchida, H. M. Kim, F. Miyaji, T. Kokubo and T. Nakamura: Biomater. 23 (2002) 313-317. 